\title{
Carbon-ion radiotherapy for lymph node oligo-recurrence: a multi-institutional study by the Japan Carbon-Ion Radiation Oncology Study Group (J-CROS)
}

\author{
Noriyuki Okonogi ${ }^{1} \cdot$ Takuya Kaminuma $^{2} \cdot$ Tomoaki Okimoto $^{3}$ - Makoto Shinoto ${ }^{4}$ - Naoyoshi Yamamoto ${ }^{1}$. \\ Shigeru Yamada ${ }^{1} \cdot$ Kazutoshi Murata $^{2} \cdot$ Tatsuya Ohno $^{2} \cdot$ Yoshiyuki Shioyama $^{4} \cdot$ Hiroshi Tsuji $^{1} \cdot$ Takashi Nakano $^{2}$. \\ Tadashi Kamada ${ }^{1}$
}

Received: 10 February 2019 / Accepted: 2 April 2019 / Published online: 9 April 2019

(c) The Author(s) 2019

\begin{abstract}
Background The efficacy of carbon-ion radiotherapy (C-ion RT) for lymph node (LN) oligo-recurrence has only been evaluated in limited single-center studies. We aimed to investigate the benefit of C-ion RT for LN oligo-recurrence in a large multi-center study.

Methods Patients who received C-ion RT between December 1996 and December 2015 at 4 participating facilities and who met the following eligibility criteria were included: (i) histological or clinical diagnosis of LN recurrence; (ii) controlled primary lesion; (iii) no recurrence other than LN; (iv) LN recurrence involved in a single lymphatic site; and (v) age $\geq 20$ years. Results A total of 323 patients were enrolled. Median follow-up period was 34 months for surviving patients. The most common dose fractionation of C-ion RT was 48.0 Gy (relative biological effectiveness) in 12 fractions. Forty-seven patients had a history of RT at the recurrent site. The 2-year local control (LC) and overall survival (OS) rates after C-ion RT were $85 \%$ and $63 \%$, respectively. Only 1 patient developed grade- 3 toxicity. Factors such as LN diameter, histology, and history of previous RT did not correlate with LC. Smaller diameters $(<30 \mathrm{~mm})$ and numbers $(\leq 3)$ of LN metastases as well as longer disease-free intervals post-primary therapy ( $\geq 16$ months) were associated with significantly better OS.

Conclusions $\mathrm{C}$-ion RT for LN oligo-recurrence appeared to be effective and safe. C-ion RT may provide a survival benefit to patients with LN oligo-recurrence, particularly to those with few LN metastases, smaller LN diameters, and longer diseasefree intervals.
\end{abstract}

Keywords Carbon-ion radiotherapy $\cdot$ Radiotherapy $\cdot$ Lymph nodes metastasis $\cdot$ Oligo-recurrence

Electronic supplementary material The online version of this article (https://doi.org/10.1007/s10147-019-01440-y) contains supplementary material, which is available to authorized users.

Tadashi Kamada

kamada.tadashi@qst.go.jp

1 QST Hospital, National Institutes for Quantum and Radiological Science and Technology, 4-9-1 Anagawa, Inage-ku, Chiba 263-8555, Japan

2 Department of Radiation Oncology, Gunma University Graduate School of Medicine, Maebashi, Gunma, Japan

3 Department of Radiology, Hyogo Ion Beam Medical Center, Tatsuno, Hyogo, Japan

4 Ion Beam Therapy Center, SAGA HIMAT Foundation, Saga, Japan

\section{Introduction}

Metastatic tumors have traditionally been managed with systemic treatment administered with palliative intent. The presence of metastases is considered a clinical manifestation of widespread microscopic disseminated disease. To that end, the concept of oligometastases was described in 1995 as a distinct clinical entity involving limited metastatic disease [1]; it was suggested that few metastases initially exist in patients with cancer of multiple types before malignant cells acquire widespread metastatic potential [1]. Regarding this point, Niibe et al. distinguished the states of oligometastases and oligo-recurrence [2]. Oligometastases is the state in which the patient shows distant relapse in only a limited number of regions. However, the concept of oligometastases includes the state of uncontrolled primary site with several 
distant metastases. Meanwhile, oligo-recurrence means the state of recurrence or metastases with a controlled primary lesion, meaning that all metastatic sites could be cured using local therapy [2]. Consistent with this concept, many studies have demonstrated improved survival and long-term disease control after surgical resection of metastases in cancer patients with certain histological subtypes [3-7].

Surgical resection of metastatic lesions is the preferred curative treatment. However, such surgeries are sometimes restricted in patients with oligo-recurrence because of technical obstacles, patient refusal, advanced age, or associated clinical comorbidities. In recent years, state of the art radiotherapy (RT) techniques, such as stereotactic body RT (SBRT), have shown clinical benefits for patients with oligorecurrence while avoiding the risks associated with surgery $[8,9]$. Growing evidence suggests that lung and liver metastases can be treated locally using SBRT, with low toxicity and excellent outcomes $[10,11]$. However, the number of studies on the use of SBRT for lymph node (LN) metastasis is still limited.

Ion beams, such as protons and carbon ions (C-ions), provide a dose distribution that is superior to that of photons during cancer treatment. Additionally, C-ion beams are heavier than protons and provide a higher relative biological effectiveness (RBE) and thus a higher probability of tumor control, while delivering a smaller dose to the surrounding normal tissues $[12,13]$. Several studies have shown the effectiveness of C-ion RT in treating LN oligo-recurrences of radioresistant tumors or for managing recurrences after other RT methods [14-16]. These studies suggest that C-ion RT for patients with LN oligo-recurrence could be a useful treatment option. However, available data have been derived from single institutions, were limited in the type of cancers included, and were extracted from a small number of patients. Hence, we conducted a retrospective multicenter study to investigate the efficacy of $\mathrm{C}$-ion $\mathrm{RT}$ in patients with LN oligo-recurrence.

\section{Materials and methods}

\section{Eligibility}

This retrospective multicenter study was conducted within the framework of the Japan Carbon-Ion Radiation Oncology Study Group (J-CROS) and is registered with the University Hospital Medical Information Network Clinical Trials Registry (http://www.umin.ac.jp/ctr/index-j.htm), identification number UMIN000027300. The study was approved by the institutional review board of each participating institution and conducted in compliance with the Declaration of Helsinki.
Among patients who received C-ion RT between December 1996 and December 2015 at the 4 participating facilities (the Hospital of the National Institute of Radiological Sciences, Hyogo Ion Beam Medical Center, Gunma University Heavy Ion Medical Center, and the SAGA-HIMAT Foundation), those who met the following eligibility criteria were enrolled: (i) histological or clinical diagnosis of LN recurrence; (ii) controlled primary tumor; (iii) no recurrence other than that of the solitary LN; (iv) $\mathrm{LN}$ recurrence involved at a single lymphatic site; and (v) 20 years of age or older. Based on these criteria, 323 patients with LN oligo-recurrences from the 4 institutions were included in this study. An LN with a short-axis diameter of $>10 \mathrm{~mm}$ was defined as a metastatic $\mathrm{LN}$ in the present study.

\section{Treatment planning system and dose fractionation}

Patients were positioned in customized cradles and immobilized with a low-temperature thermoplastic sheet. A set of 2.0-2.5-mm-thick computed tomography (CT) images were acquired for 3-dimensional treatment planning using the HiPLAN or Xio-N system. Patients received C-ion RT daily for 4 days/week (Tuesday through Friday). The radiation dose was calculated for the target volume and is expressed in Gy (RBE), which is defined as the physical dose multiplied by the RBE of the C-ions [17]. Treatment consisted of regional LN irradiation or prophylactic irradiation and local LN boost; the clinical target volume included all swollen LNs and potentially microscopic disease. The planning target volume included the clinical target volume plus a $2-10 \mathrm{~mm}$ safety margin to account for intra- and inter-movement. The planning target volume was covered by $\geq 90 \%$ of the prescribed dose. A representative dose distribution of C-ion RT is shown in the supplementary figure. The dose fractionation schemes are listed in Table 1.

\section{Follow-up and evaluation}

Following treatment, patients had follow-up visits 1 month after treatment, then every 3-4 months for the first 2 years, and every 3-6 months thereafter. Regular follow-up studies included physical examination and diagnostic imaging (i.e., $\mathrm{CT}$ and/or magnetic resonance imaging). Local control (LC) was defined as no evidence of $\mathrm{LN}$ regrowth within the irradiated field. Progression-free survival (PFS) was defined as the absence of locoregional or distant failure or death from any cause. Overall survival (OS) and adverse events after C-ion treatment were also evaluated. Late toxicity was graded according to the Common Terminology Criteria for Adverse Events (version 4.0) [18]. The highest toxicities occurring 3 months after commencing C-ion RT were defined as late toxicities in the present study. 
Table 1 Characteristics of carbon-ion radiotherapy

\begin{tabular}{|c|c|}
\hline Dose fractionation schemes & $\begin{array}{l}\text { Number of } \\
\text { patients }\end{array}$ \\
\hline $36.0 \mathrm{~Gy}(\mathrm{RBE}) / 8 \mathrm{fr}$. & 1 \\
\hline $52.8 \mathrm{~Gy}(\mathrm{RBE}) / 8 \mathrm{fr}$. & 1 \\
\hline $60.0 \mathrm{~Gy}(\mathrm{RBE}) / 8 \mathrm{fr}$. & 1 \\
\hline 64.0 Gy (RBE)/8 fr. & 4 \\
\hline $66.0 \mathrm{~Gy}(\mathrm{RBE}) / 10 \mathrm{fr}$. & 2 \\
\hline $38.4 \mathrm{~Gy}(\mathrm{RBE}) / 12 \mathrm{fr}$. & 1 \\
\hline $40.0 \mathrm{~Gy}(\mathrm{RBE}) / 12 \mathrm{fr}$. & 2 \\
\hline 43.2 Gy (RBE)/12 fr. & 2 \\
\hline $44.0 \mathrm{~Gy}(\mathrm{RBE}) / 12 \mathrm{fr}$. & 1 \\
\hline 45.6 Gy (RBE)/12 fr. & 8 \\
\hline $48.0 \mathrm{~Gy}(\mathrm{RBE}) / 12 \mathrm{fr}$. & 114 \\
\hline $50.4 \mathrm{~Gy}(\mathrm{RBE}) / 12 \mathrm{fr}$. & 7 \\
\hline $51.6 \mathrm{~Gy}(\mathrm{RBE}) / 12 \mathrm{fr}$. & 1 \\
\hline $52.8 \mathrm{~Gy}(\mathrm{RBE}) / 12 \mathrm{fr}$. & 101 \\
\hline $55.2 \mathrm{~Gy}(\mathrm{RBE}) / 12 \mathrm{fr}$. & 14 \\
\hline $57.6 \mathrm{~Gy}(\mathrm{RBE}) / 12 \mathrm{fr}$. & 14 \\
\hline $64.8 \mathrm{~Gy}(\mathrm{RBE}) / 12 \mathrm{fr}$. & 1 \\
\hline $72.0 \mathrm{~Gy}(\mathrm{RBE}) / 12 \mathrm{fr}$. & 1 \\
\hline $52.0 \mathrm{~Gy}(\mathrm{RBE}) / 13 \mathrm{fr}$. & 1 \\
\hline $50.4 \mathrm{~Gy}(\mathrm{RBE}) / 14 \mathrm{fr}$. & 1 \\
\hline $52.8 \mathrm{~Gy}(\mathrm{RBE}) / 16 \mathrm{fr}$. & 8 \\
\hline $56.0 \mathrm{~Gy}(\mathrm{RBE}) / 16 \mathrm{fr}$. & 1 \\
\hline $57.6 \mathrm{~Gy}(\mathrm{RBE}) / 16 \mathrm{fr}$. & 10 \\
\hline $60.8 \mathrm{~Gy}(\mathrm{RBE}) / 16 \mathrm{fr}$. & 1 \\
\hline $64.0 \mathrm{~Gy}(\mathrm{RBE}) / 16 \mathrm{fr}$. & 9 \\
\hline $60.0 \mathrm{~Gy}(\mathrm{RBE}) / 20 \mathrm{fr}$. & 1 \\
\hline $65.0 \mathrm{~Gy}(\mathrm{RBE}) / 25 \mathrm{fr}$. & 1 \\
\hline $65.0 \mathrm{~Gy}(\mathrm{RBE}) / 26 \mathrm{fr}$. & 6 \\
\hline $70.2 \mathrm{~Gy}(\mathrm{RBE}) / 26 \mathrm{fr}$. & 4 \\
\hline $70.4 \mathrm{~Gy}(\mathrm{RBE}) / 32 \mathrm{fr}$. & 2 \\
\hline $74.0 \mathrm{~Gy}(\mathrm{RBE}) / 37 \mathrm{fr}$. & 2 \\
\hline
\end{tabular}

$R B E$ relative biological effectiveness, $f r$. fractions

\section{Statistical analysis}

The incidences of LC, OS, and PFS were determined using the Kaplan-Meier method. These endpoints were calculated from the initiation of $\mathrm{C}$-ion $\mathrm{RT}$ to the date of last follow-up or death from any cause. The log-rank test was used for univariate analyses. All factors with statistically significant associations in the univariate analysis were included in the multivariate analysis, and a Cox proportional hazards regression model was used. $p$ values $<0.05$ were considered significant; all statistical tests were twosided. Statistical calculations were performed using the IBM SPSS Statistics 24 software (IBM, Armonk, NY, USA).
Table 2 Patient and tumor characteristics $(n=323)$

\begin{tabular}{lc}
\hline Characteristic & $n(\%)$ \\
\hline Age (years), median (range) & $66(29-90)$ \\
LN diameter in maximal length (mm), median (range) & $22(10-80)$ \\
Number of LNs & \\
1 & $215(66.6)$ \\
2 & $65(20.1)$ \\
3 & $15(4.6)$ \\
$\geq 4$ & $28(8.7)$ \\
History of radiotherapy to the lesion & \\
No (initial irradiation) & $276(85.4)$ \\
Yes (re-irradiation) & $47(14.6)$ \\
Disease-free interval (months), median (range) & $16(1-247)$ \\
Histology & \\
SCC & $66(20.4)$ \\
Non-SCC & $257(79.6)$ \\
Primary site of carcinomas & \\
Head and neck & $17(5.3)$ \\
Lung & $99(30.7)$ \\
Breast & $4(1.2)$ \\
Upper GI (esophagus, stomach, duodenum) & $26(8.0)$ \\
Lower GI (colon, rectum) & $77(23.8)$ \\
Pancreas & $20(6.2)$ \\
Liver, cholecyst, bile duct & $11(3.4)$ \\
Urinary system (kidney, renal pelvis, bladder) & $8(2.5)$ \\
Prostate & $7(2.2)$ \\
Uterine & $38(11.8)$ \\
Ovary & $8(2.5)$ \\
Primary unknown & $1(0.3)$ \\
Others (vagina, skin, chordoma, adrenal gland) & $7(2.2)$ \\
\hline & \\
& \\
&
\end{tabular}

$L N$ metastatic lymph node, $S C C$ squamous cell carcinoma, GI gastrointestinal tract

\section{Results}

\section{Cohort characteristics}

Patient and tumor characteristics are summarized in Table 2. The median patient age was 66 years (range, 29-90 years), and the median maximal LN diameter was $22 \mathrm{~mm}$ (range, $10-80 \mathrm{~mm}$ ). The median disease-free interval (i.e., the time between primary treatment administration and the day of recurrence detection) was 16 months (range, 1-247 months). Sixty-six patients were diagnosed with squamous cell carcinoma (SCC), while the remaining 257 patients were diagnosed with non-SCC (including adenocarcinoma, adenosquamous carcinoma, and other carcinomas). 


\section{Treatment efficacy and prognostic factors}

The median follow-up period was 34 months (range, 2-181 months) for surviving patients. The 2-year LC, OS, and PFS rates were $85.4 \%$ (95\% confidence interval [CI] 81.0-89.9\%), 62.9\% (95\% CI 57.4-68.4\%), and 33.5\% (95\% CI 28.3-38.7\%), respectively (Fig. 1). Site-specific clinical results (the 5 most common primary sites) are shown in Supplementary Table 1. Table 3 lists the results of the log-rank tests for prognostic factors. Regarding the setting of cutoff values in the univariate or multivariate analysis, median values were used as the cutoff for age (66 years) and disease-free interval (16 months). The cutoff value for $\mathrm{LN}$ diameter was set as $30 \mathrm{~mm}$ based on previous studies [19, 20]. In addition, the analyses for the number of LNs were conducted between 2 groups ( $1-3$ versus $\geq 4)$ based on a previous study [21]. None of the analyzed factors, including LN diameter and histology, were significantly correlated with LC in the univariate analysis. However, the number of LN metastases was associated with PFS. Furthermore, the $\mathrm{LN}$ diameter (maximum length), number of LN metastases, and disease-free interval were associated with OS. The factors that were significant in the univariate analysis were then assessed to identify predictors of clinical outcomes using multivariate analyses based on the Cox proportional hazards model (Table 4). A smaller number $(\leq 3)$ of $\mathrm{LN}$ metastases was associated with significantly better PFS $(p=0.047)$. Moreover, a smaller LN diameter $(<30 \mathrm{~mm})(p=0.011)$, smaller number $(\leq 3)$ of LN metastases $(p=0.006)$, and longer disease-free interval ( $\geq 16$ months) following primary therapy $(p=0.003)$ were associated with significantly better OS.

\section{Toxicities}

All patients completed their planned C-ion RT except for 1 who developed grade 2 esophagitis; this patient received 50.4 Gy (RBE) in 14 fractions and ceased treatment. The esophagitis resolved after treatment, and no late toxicity was observed in this patient. As shown in Supplementary Table 2, 15 patients (4.6\%) developed grade $\geq 2$ late toxicities [Supplementary Table 2(A)]; of these, 1 developed severe (grade 3) late toxicity [Supplementary Table 2(B)]. The patient who developed grade 3 late toxicity had originally undergone surgery for tongue carcinoma; this patient received C-ion $\mathrm{RT}$ at a dose of $65.0 \mathrm{~Gy}(\mathrm{RBE})$ in 26 fractions for submandibular LN and subsequently developed grade 3 facial nerve disorder.

\section{Discussion}

Ours is the first multicenter study to investigate the efficacy of C-ion RT in patients with LN oligo-recurrence. Few published data exist regarding the use of conventional RT in the context of LN oligo-recurrence. However, reports of the clinical outcomes of patients with LN oligo-recurrence who underwent SBRT have been published in recent years; Table 5 lists the published studies of patients with LN oligo-recurrence in which the median follow-up times
Fig. 1 Kaplan-Meier curves of local control (green), overall survival (red), and progressionfree survival (blue) for all 323 patients. The numbers at risk are shown below the figure. $C I$ confidence interval, $L C$ local control, $P F S$ progression-free survival, $O S$ overall survival

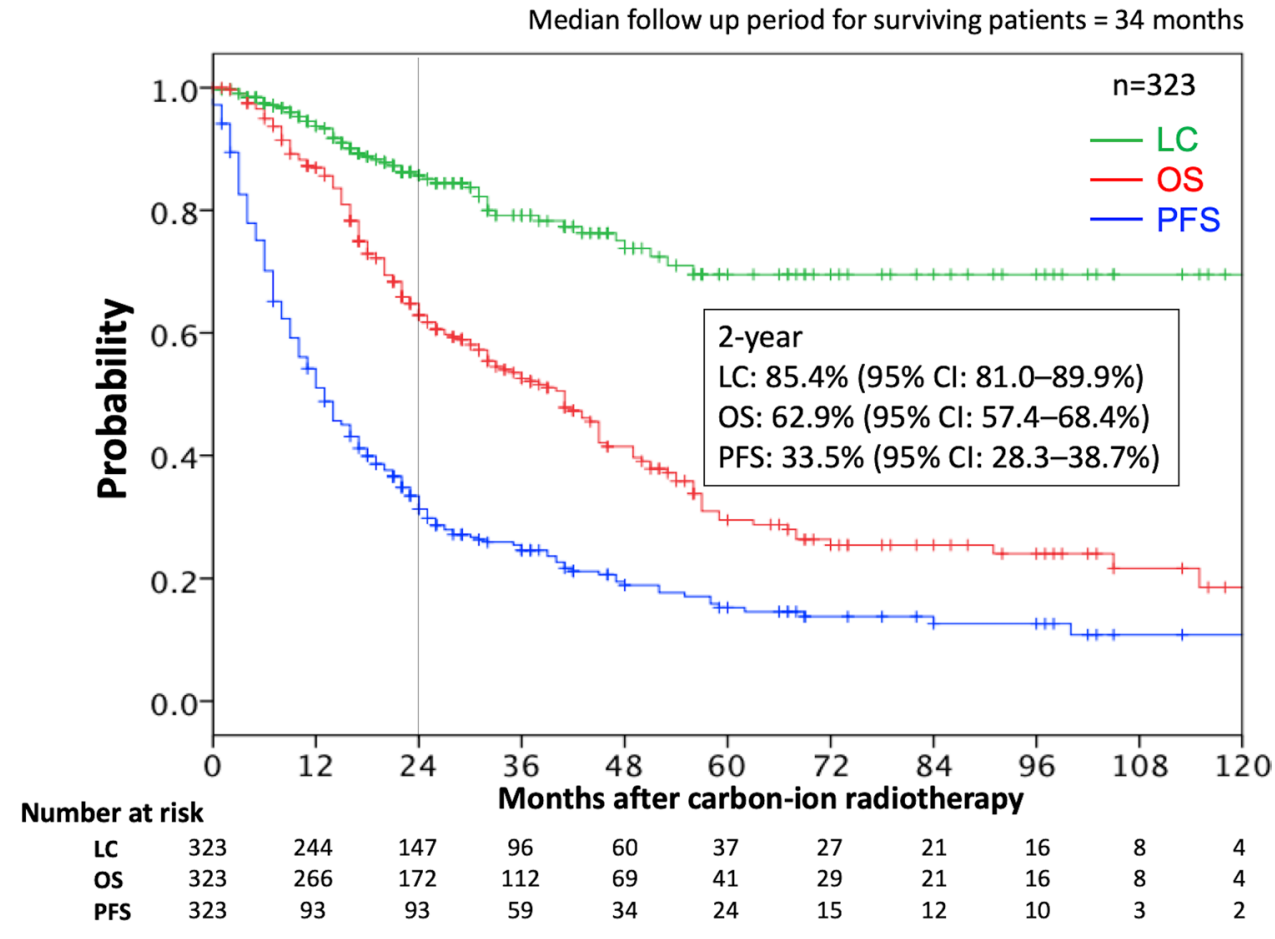


Table 3 Assessment of prognostic factors with univariate analysis

\begin{tabular}{|c|c|c|c|c|c|c|c|}
\hline \multirow[t]{2}{*}{ Factor } & \multirow{2}{*}{$\begin{array}{l}\text { Number of } \\
\text { patients }\end{array}$} & \multicolumn{2}{|l|}{$\mathrm{LC}$} & \multicolumn{2}{|l|}{ PFS } & \multicolumn{2}{|l|}{ OS } \\
\hline & & 2-year (\%) & $p$ value & 2-year (\%) & $p$ value & 2-year (\%) & $p$ value \\
\hline Age (years) & & & 0.235 & & 0.114 & & 0.664 \\
\hline$<66$ & 154 & 80.4 & & 27.0 & & 61.4 & \\
\hline$\geq 66$ & 169 & 89.6 & & 35.3 & & 64.2 & \\
\hline LN diameter in maximal length (mm) & & & 0.485 & & 0.056 & & 0.010 \\
\hline$<30$ & 229 & 85.4 & & 34.2 & & 68.8 & \\
\hline$\geq 30$ & 94 & 86.1 & & 24.5 & & 48.6 & \\
\hline Number of LNs & & & 0.242 & & 0.023 & & 0.001 \\
\hline $1-3$ & 295 & 86.5 & & 33.1 & & 65.2 & \\
\hline$\geq 4$ & 28 & 67.3 & & 12.5 & & 38.9 & \\
\hline History of radiotherapy to the lesion & & & 0.394 & & 0.009 & & 0.016 \\
\hline No (initial irradiation) & 276 & 84.8 & & 28.9 & & 61.5 & \\
\hline Yes (re-irradiation) & 47 & 88.9 & & 45.7 & & 70.7 & \\
\hline Histology & & & 0.703 & & 0.585 & & 0.181 \\
\hline $\mathrm{SCC}$ & 66 & 83.8 & & 29.3 & & 54.1 & \\
\hline Non-SCC & 257 & 85.7 & & 31.9 & & 65.3 & \\
\hline Disease-free interval (months) & & & 0.269 & & 0.324 & & 0.001 \\
\hline$<16$ & 162 & 81.9 & & 25.8 & & 53.2 & \\
\hline$\geq 16$ & 161 & 88.6 & & 37.0 & & 72.6 & \\
\hline
\end{tabular}

$L N$ metastatic lymph node, $S C C$ squamous cell carcinoma, $E Q D_{2}$ equivalent dose in 2-Gy fraction, $L C$ local control, $P F S$ progression-free survival, $O S$ overall survival

Table 4 Assessment of prognostic factors with multivariate analysis

\begin{tabular}{|c|c|c|c|c|}
\hline \multirow[t]{2}{*}{ Factor } & \multicolumn{2}{|l|}{ PFS } & \multicolumn{2}{|l|}{ OS } \\
\hline & $p$ value & $\operatorname{HR}(95 \% \mathrm{CI})$ & $p$ value & HR $(95 \%$ CI $)$ \\
\hline $\mathrm{LN}$ size in maximal length $<30 \mathrm{~mm}$ & & & 0.011 & $0.668(0.490-0.912)$ \\
\hline Number of LNs (1-3) & 0.047 & $0.658(0.435-0.995)$ & 0.006 & $0.535(0.341-0.837)$ \\
\hline History of RT to the lesion (re-irradiation) & - & & - & \\
\hline Disease-free interval $\geq 16$ months & & & 0.003 & $0.629(0.466-0.851)$ \\
\hline
\end{tabular}

$L N$ metastatic lymph node, $S C C$ squamous cell carcinoma, $P F S$ progression-free survival, $O S$ overall survival, $C I$ confidence interval, $H R$ hazard ratio were $\geq 12$ months [19, 22-29]. Although these studies are heterogeneous in terms of site, primary histology, and dose, the control rates for treated metastatic LNs were 64-78\%, except for patients with prostate cancer. The present study showed a 2-year LC of $85.4 \%$ despite the larger number of patients, the majority of whom had non-SCCs $(79.6 \%)$ and among whom prostate cancer was rare $(2.2 \%)$. Thus, C-ion $\mathrm{RT}$ can be a powerful focal therapy for patients with $\mathrm{LN}$ oligo-recurrence.

Previous studies found that LN diameter and volume may be predictors of in-field control $[19,30]$. The information in Table 5 implies that patients with LN oligo-recurrence of prostate cancer had better LC rates. Regarding the association between LC in patients with irradiated LNs and histological tumor type, Milano et al. reported a better LC rate in patients with breast cancer than in those with non-breast cancers [31]. However, other factors, such as LN diameter or histology, did not significantly affect LC in the univariate analysis in the present study. Notably, a history of RT at the site of recurrence did not compromise LC, which is consistent with recent studies investigating $\mathrm{C}$-ion $\mathrm{RT}$ for $\mathrm{LN}$ recurrence $[15,16]$. Additionally, our study revealed that $\mathrm{C}$-ion RT for LN oligo-recurrence caused relatively few late toxicities, with only 1 patient developing grade 3 late toxicity. Thus, C-ion RT appears to be beneficial for conventionally difficult-to-cure patients with $\mathrm{LN}$ oligo-recurrence.

Several researchers reported an association between dose fractionation and in-field control when using SBRT for LN oligo-recurrence. Bae et al. found that a dose of 48 Gy or greater in 3 fractions was associated with better in-field control in a series of 41 patients with colorectal cancer metastases [26]. Conde-Moreno et al. proposed using 
Table 5 Clinical outcomes of SBRT and present study for lymph node oligo-recurrence

\begin{tabular}{|c|c|c|c|c|c|c|c|}
\hline Author (references) & Year & $\begin{array}{l}\text { Num- } \\
\text { ber of } \\
\text { patients }\end{array}$ & Primary disease & Dose fractionation & $\begin{array}{l}\text { Median } \\
\text { follow-up time } \\
\text { (months) }\end{array}$ & Local control & Grade $\geq 3$ late toxicity \\
\hline Kim et al. [22] & 2008 & 23 & Colorectal & $30-51 \mathrm{~Gy} / 3 \mathrm{fr}$. & 31 & $74 \%$ at 4 years & $\begin{array}{l}4 \% \text { (Grade } 4 \text { in } 1 \\
\text { patient) }\end{array}$ \\
\hline Choi et al. [19] & 2009 & 30 & Uterine & $33-45 \mathrm{~Gy} / 3 \mathrm{fr}$. & 15 & $67 \%$ at 4 years & $20 \%$ \\
\hline Kim et al. [23] & 2009 & 7 & Gastric & $48 \mathrm{~Gy} / 3$ fr. (median) & 26 & NR & $0 \%$ \\
\hline Bignardi et al. [24] & 2011 & 19 & Mixed & 45 Gy/6 fr. (median) & 12 & $78 \%$ at 2 years & $5 \%$ \\
\hline $\begin{array}{l}\text { Casamassima et al. } \\
{[25]}\end{array}$ & 2011 & 25 & Prostate & $\begin{array}{l}30 \mathrm{~Gy} / 3 \text { fr. (most com- } \\
\text { mon) }\end{array}$ & 29 & $90 \%$ at 3 years & $0 \%$ \\
\hline Bea et al. [26] & 2012 & 41 & Colorectal & 48 Gy/3 fr. (median) & 28 & $64 \%$ at 3 years & $7 \%$ \\
\hline Wang et al. [27] & 2016 & 85 & Mixed & $\begin{array}{l}45 \mathrm{~Gy} / 5 \text { fr. (most com- } \\
\text { mon) }\end{array}$ & 27 & $77 \%$ at 5 years & $\begin{array}{l}\text { 7\% (Grade } 5 \text { in } 3 \\
\text { patients) }\end{array}$ \\
\hline Napieralska et al. [28] & 2016 & 18 & Prostate & 30 Gy/3 fr. (median) & 16 & $70 \%$ at 2 years & NR \\
\hline $\begin{array}{l}\text { Jereczek-Fossa et al. } \\
\text { [29] }\end{array}$ & 2017 & 94 & Prostate & 33 Gy/3 fr. (median) & 19 & $84 \%$ at 2 years & $0 \%$ \\
\hline Present study & 2019 & 323 & Mixed & $\begin{array}{l}48 \text { Gy }(\mathrm{RBE}) / 12 \mathrm{fr} . \\
\text { (most common) }\end{array}$ & $25(34)^{\mathrm{a}}$ & $85 \%$ at 2 years & $\begin{array}{l}0 \% \mathrm{~b} \text { (Grade } 3 \text { in } 1 \\
\text { patient) }\end{array}$ \\
\hline
\end{tabular}

$S B R T$ stereotactic body radiotherapy, $f r$. fractions, $R B E$ relative biological effectiveness, $N R$ not reported

${ }^{a}$ Median follow-up period for surviving patients

${ }^{\mathrm{b}} 0.31 \%$ (one out of 323 patients) for the record

dose fractionation schemes of either 6 fractions of $7.5 \mathrm{~Gy}$ or 3 fractions of $\geq 10 \mathrm{~Gy}$ based on criteria that depended on the tolerance of the surrounding structures [20]. However, univariate analysis revealed no significant difference in LC according to the C-ion RT dose in our study; this could be owing to the variety of maximum $\mathrm{LN}$ diameters, which ranged from 10 to $80 \mathrm{~mm}$. Prospective trials to determine the optimal C-ion RT dose fractionation scheme for LN oligorecurrence are warranted.

In our study, having $\leq 3 \mathrm{LN}$ metastases was associated with significantly better PFS. Moreover, LNs with a diameter $<30 \mathrm{~mm}$, having $\leq 3 \mathrm{LN}$ metastases, and a disease-free interval $\geq 16$ months after the initial therapy were associated with significantly better OS. These findings support the notion of an oligo-recurrence state in which aggressive local therapy can provide a survival benefit in a specific population. Regarding prognostic factors reported in the literature, Salama et al. reported that patients with $\leq 3$ metastases had better PFS and OS than those with 4-5 metastases [21]. Although their cohorts included multisite extracranial oligo-recurrence that were not confined to LNs, our results support their findings. Jereczek-Fossa et al. reported that a larger LN volume compromised LC and predicted a poorer prognosis; an abdominal gross tumor volume of $17 \mathrm{~cm}^{3}$ or smaller predicted favorable PFS; and each additional $1 \mathrm{~cm}^{3}$ was associated with a $1 \%$ worsening in PFS [32]. Although LN diameter did not affect the LC rate in our study, it did affect OS. Thus, LN diameter may be a prognostic factor in certain patients with LN oligo-recurrence, as may the disease-free interval post-primary therapy. Zhang et al. reported that a disease-free interval of more than 12 months was significantly related to longer OS in patients with lung metastases who received SBRT [33]. Furthermore, other researchers have reported that a longer disease-free interval was significantly associated with longer OS in patients with extracranial oligo-recurrence or recurrent hepatocellular carcinoma following SBRT [34, 35]. These results, as well as those of our study, indicate that C-ion RT should be considered in patients with LN oligo-recurrence, particularly in patients with a longer disease-free interval.

The present study has some limitations. First, the study design was retrospective; therefore, various dose fractionation protocols were included. Second, the median follow-up period was short ( 25 months). Longer follow-up is needed to determine the long-term efficacy and toxicity of C-ion RT.

In conclusion, our study demonstrates that $\mathrm{C}$-ion $\mathrm{RT}$ for LN oligo-recurrence appears to be effective and safe. In addition, C-ion RT may improve LC irrespective of tumor status and may produce a survival benefit in patients with LN oligo-recurrence. In particular, patients who have a small number of LN metastases $(\leq 3)$, smaller LN diameter $(<30 \mathrm{~mm})$, and longer disease-free interval ( $\geq 16$ months) are most likely to achieve a survival benefit from C-ion RT.

Acknowledgements We wish to thank the members of the Working Group of Metastatic Tumors, part of the Japan Carbon-Ion Radiation Oncology Study Group, for their constructive criticism and advice. This research did not receive any specific grant from funding agencies in the public, commercial, or not-for-profit sectors. 


\section{Compliance with ethical standards}

Conflict of interest No author has any conflict of interest.

Open Access This article is distributed under the terms of the Creative Commons Attribution 4.0 International License (http://creativeco mmons.org/licenses/by/4.0/), which permits unrestricted use, distribution, and reproduction in any medium, provided you give appropriate credit to the original author(s) and the source, provide a link to the Creative Commons license, and indicate if changes were made.

\section{References}

1. Hellman S, Weichselbaum RR (1995) Oligometastases. J Clin Oncol 1995(13):8-10

2. Niibe Y, Hayakawa K (2010) Oligometastases and oligo-recurrence: the new era of cancer therapy. Jpn J Clin Oncol 40:107111. https://doi.org/10.1093/jjco/hyp167

3. Ripley RT, Downey RJ (2014) Pulmonary metastasectomy. J Surg Oncol 2014(109):42-46. https://doi.org/10.1002/jso.23450

4. Ruiterkamp J, Ernst MF (2011) The role of surgery in metastatic breast cancer. Eur J Cancer 47:S6-S22. https://doi.org/10.1016/ S0959-8049(11)70142-3

5. Casiraghi M, De Pas T, Maisonneuve P et al (2011) A 10-year single-center experience on 708 lung metastasectomies: the evidence of the international registry of lung metastases. J Thorac Oncol 6:1373-1378. https://doi.org/10.1097/JTO.0b013e3182 $208 \mathrm{e} 58$

6. Kanemitsu Y, Kato T, Hirai T et al (2004) Preoperative probability model for predicting overall survival after resection of pulmonary metastases from colorectal cancer. Br J Surg 91:112-120

7. Pawlik TM, Scoggins CR, Zorzi D et al (2005) Effect of surgical margin status on survival and site of recurrence after hepatic resection for colorectal metastases. Ann Surg 241:715-724

8. Milano MT, Philip A, Okunieff P (2009) Analysis of patients with oligometastases undergoing two or more curative-intent stereotactic radiotherapy courses. Int J Radiat Oncol Biol Phys 73:832-837. https://doi.org/10.1016/j.ijrobp.2008.04.073

9. Tree AC, Khoo VS, Eeles RA et al (2013) Stereotactic body radiotherapy for oligometastases. Lancet Oncol 14:e28-e37. https://doi. org/10.1016/S1470-2045(12)70510-7

10. Ricco A, Davis J, Rate W et al (2017) Lung metastases treated with stereotactic body radiotherapy: the RSSearch ${ }^{\circledR}$ patient Registry's experience. Radiat Oncol 12:35. https://doi.org/10.1186/ s13014-017-0773-4

11. Mahadevan A, Blanck O, Lanciano R et al (2018) Stereotactic Body Radiotherapy (SBRT) for liver metastasis - clinical outcomes from the international multi-institutional RSSearch ${ }^{\circledR}$ Patient Registry. Radiat Oncol 13:26. https://doi.org/10.1186/ s13014-018-0969-2

12. Kanai T, Furusawa Y, Fukutsu K et al (1997) Irradiation of mixed beam and design of spread-out Bragg peak for heavy-ion radiotherapy. Radiat Res 147:78-85

13. Kanai T, Endo M, Minohara S et al (1999) Biophysical characteristics of HIMAC clinical irradiation system for heavy-ion radiation therapy. Int J Radiat Oncol Biol Phys 44:201-210

14. Isozaki Y, Yamada S, Kawashiro S et al (2017) Carbon-ion radiotherapy for isolated para-aortic lymph node recurrence from colorectal cancer. J Surg Oncol 116:932-938. https://doi.org/10.1002/ jso. 24757

15. Tamaki T, Ohno T, Kiyohara $\mathrm{H}$ et al (2013) Carbon-ion radiotherapy for marginal lymph node recurrences of cervical cancer after definitive radiotherapy: a case report. Radiat Oncol 8:79. https://doi.org/10.1186/1748-717X-8-79

16. Shiba S, Okonogi N, Kato S et al (2017) Clinical impact of reirradiation with carbon-ion radiotherapy for lymph node recurrence of gynecological cancers. Anticancer Res 37:5577-5583

17. Inaniwa $\mathrm{T}$, Kanematsu N, Matsufuji $\mathrm{N}$ et al (2015) Reformulation of a clinical-dose system for carbon-ion radiotherapy treatment planning at the National Institute of Radiological Sciences, Japan. Phys Med Biol 60:3271-3286. https://doi. org/10.1088/0031-9155/60/8/3271

18. NCI Common Terminology Criteria for Adverse Events (CTCAE) v4.0 data files. http://evs.nci.nih.gov/ftp1/CTCAE/ About.html. Accessed 20 June 2018

19. Choi CW, Cho CK, Yoo SY et al (2009) Image-guided stereotactic body radiation therapy in patients with isolated paraaortic lymph node metastases from uterine cervical and corpus cancer. Int J Radiat Oncol Biol Phys 74:147-153. https://doi. org/10.1016/j.ijrobp.2008.07.020

20. Conde-Moreno AJ, Lopez-Guerra JL, Macias VA et al (2016) Spanish Society of Radiation Oncology clinical guidelines for stereotactic body radiation therapy in lymph node oligometastases. Clin Transl Oncol 18:342-351. https://doi.org/10.1007/ s12094-015-1383-y

21. Salama JK, Hasselle MD, Chmura SJ et al (2012) Stereotactic body radiotherapy for multisite extracranial oligometastases: final report of a dose escalation trial in patients with 1 to 5 sites of metastatic disease. Cancer 118:2962-2970. https://doi. org/10.1002/cncr.26611

22. Kim MS, Choi C, Yoo S et al (2008) Stereotactic body radiation therapy in patients with pelvic recurrence from rectal carcinoma. Jpn J Clin Oncol 38:695-700. https://doi.org/10.1093/ $\mathrm{jjco} / \mathrm{hyn} 083$

23. Kim MS, Yoo SY, Cho CK et al (2009) Stereotactic body radiotherapy for isolated para-aortic lymph node recurrence after curative resection in gastric cancer. J Korean Med Sci 24:488 492. https://doi.org/10.3346/jkms.2009.24.3.488

24. Bignardi M, Navarria P, Mancosu P et al (2011) Clinical outcome of hypofractionated stereotactic radiotherapy for abdominal lymph node metastases. Int J Radiat Oncol Biol Phys 81:831-838

25. Casamassima F, Masi L, Menichelli C et al (2011) Efficacy of eradicative radiotherapy for limited nodal metastases detected with choline PET scan in prostate cancer patients. Tumori 97:49-55

26. Bae SH, Kim MS, Cho CK et al (2012) High dose stereotactic body radiotherapy using three fractions for colorectal oligometastases. J Surg Oncol 106:138-143. https://doi.org/10.1002/ jso. 23058

27. Wang HH, Zaorsky NG, Meng MB et al (2016) Stereotactic radiation therapy for oligometastases or oligorecurrence within mediastinal lymph nodes. Oncotarget 7:18135-18145. https://doi. org/10.18632/oncotarget.7636

28. Napieralska A, Miszczyk L, Stąpór-Fudzińska M (2016) CyberKnife stereotactic ablative radiotherapy as an option of treatment for patients with prostate cancer having oligometastatic lymph nodes: single-center study outcome evaluation. Technol Cancer Res Treat 15:661-673. https://doi.org/10.1177/15330 34615595945

29. Jereczek-Fossa BA, Fanetti G, Fodor C et al (2017) Salvage stereotactic body radiotherapy for isolated lymph node recurrent prostate cancer: single institution series of 94 consecutive patients and 124 lymph nodes. Clin Genitourin Cancer. 15:e623-e632. https:// doi.org/10.1016/j.clgc.2017.01.004

30. Bacorro W, Dumas I, Escande A et al (2018) Dose-volume effects in pathologic lymph nodes in locally advanced cervical cancer. 
Gynecol Oncol 148:461-467. https://doi.org/10.1016/j.ygyno 2017.12.028

31. Milano MT, Katz AW, Zhang $\mathrm{H}$ et al (2012) Oligometastases treated with stereotactic body radiotherapy: long-term follow-up of prospective study. Int J Radiat Oncol Biol Phys 83:878-886. https://doi.org/10.1016/j.jirobp.2011.08.036

32. Jereczek-Fossa BA, Beltramo G, Fariselli L et al (2012) Robotic image-guided stereotactic radiotherapy, for isolated recurrent primary, lymph node or metastatic prostate cancer. Int J Radiat Oncol Biol Phys 82:889-897. https://doi.org/10.1016/j.ijrob p.2010.11.031

33. Zhang Y, Xiao JP, Zhang HZ et al (2011) Stereotactic body radiation therapy favors long-term overall survival in patients with lung metastases: five-year experience of a single-institution. Chin Med J 124:4132-4137
34. Sole CV, Lopez Guerra JL, Matute R et al (2013) Stereotactic ablative radiotherapy delivered by image-guided helical tomotherapy for extracranial oligometastases. Clin Transl Oncol 15:484-491. https://doi.org/10.1007/s12094-012-0956-2

35. Bae SH, Park HC, Lim DH et al (2012) Salvage treatment with hypofractionated radiotherapy in patients with recurrent small hepatocellular carcinoma. Int J Radiat Oncol Biol Phys 82:e603e607. https://doi.org/10.1016/j.ijrobp.2011.09.053

Publisher's Note Springer Nature remains neutral with regard to jurisdictional claims in published maps and institutional affiliations. 